\title{
ANTICANCER ACTIVITY OF SILVER NANOBIOCONJUGATES SYNTHESISED FROM PIPER BETLE LEAVES EXTRACT AND ITS ACTIVE COMPOUND EUGENOL
}

\author{
R. PREETHI, P. R. PADMA \\ Department of Biochemistry, Biotechnology and Bioinformatics, Avinashilingam Institute for Home Science and Higher Education for \\ Women, Coimbatore, Tamil Nadu \\ Email: padma_bc@avinuty.ac.in
}

Received: 21 May 2016 Revised and Accepted: 22 Jul 2016

\begin{abstract}
Objective: Our present study deals with the anticancer property of silver nano bio conjugates synthesized from the methanolic extract of Piper betle leaves and the pure compound eugenol.

Methods: The anticancer activity of the nano bio conjugates synthesized from the extract and pure compound, in comparison with their respective non-conjugated raw material, were studied using cancer cell lines. The anticancer activity was analyzed by cell viability and staining techniques. The cell viability was determined by the MTT assay and the apoptosis was evaluated by the AO/EtBr staining method, which was carried out in both the cancerous (oral carcinoma (KB) cell lines) and non-cancerous cells (primary cultured human buccal cells). The phase of cell death was assessed by the flow cytometry followed by the cytotoxicity assessment.
\end{abstract}

Results: The results revealed that Piper betle leaves as well as their active phenolic compound eugenol exhibited strong anticancer activity in KB oral carcinoma cells. The anticancer effect of the extract was attributable to the component phenolics, eugenol respectively in betel leaves, as the phenolics also exhibited strong cytotoxicity in cancer cells. The anticancer activity increased by a marked magnitude when the extract/compound was administered as nano-bio conjugates. The significant observation was the differential effect evoked by the AgNPs, which was non-toxic to noncancerous buccal cells while evoking a strong cytotoxicity in the cancer cells.

Conclusion: The results proved that the phytoconstituents like phenols in the betel leaves play a major role in the reduction of nano bio conjugates. The anticancer properties of silver nano bio conjugates were higher in the conjugated nanoform than the non-conjugated form.

Keywords: Piper betle, Eugenol, Nano bio conjugates, Anticancer, KB cells

(C) 2016 The Authors. Published by Innovare Academic Sciences Pvt Ltd. This is an open access article under the CC BY license (http://creativecommons. org/licenses/by/4. 0/) DOI: http://dx.doi.org/10.22159/ijpps.2016.v8i9.12993

\section{INTRODUCTION}

Currently about $50 \%$ of cancers in men and $20 \%$ of cancers in women are related to tobacco use, which has led to oral cancer death in the age group of 35-64 y. Developing countries of the South Asian region have a higher incidence of oral cancer compared to developed countries [1, 2]. The standard treatment followed all over the world is radiation therapy, or a combination of radiation therapy, chemotherapy and surgical removal of cancer. In spite of such interventions, cancer continues to take lives. Researchers are also intensifying their efforts on various therapy and trails on immunotherapy, antiangiogenic therapy, gene and viral therapy, cancer stem cell therapy and targeted therapy [3]

Over the last few decades, about 85,000 compounds have been screened for cancers, but only a few could be considered as effective and promising anti-cancer drugs [4]. Recently, the field of cancer therapies has been improved by many diverse scientific disciplines in order to fight better against cancer. Nanotechnology, which involves the creation, manipulation, and application of structures in the nanometer size range, has started revolutionizing cancer diagnosis and therapy [5]. Nanomedicine represents an innovative and multidisciplinary field that exploits nanotechnology to utilize in disease diagnosis and treatment. The main feature of these nanosystems is that their surfaces can be functionalized, exploiting reactive terminal groups, with specific proteins, peptides or monoclonal antibodies that are able selectively to bind a site of action or a particular target tissue, without interacting with other cells. They also improve the stability of drugs and release the drug in a constant, uniform concentration and in a controlled system, leading to reduced side effects [6]. Nowadays nanotechnology-based approaches to overcome the problem occur in the conventional system for treatment and the diagnosis of cancer [7].

The green production of nanoparticles using naturally occurring agents such as plant extract, microorganisms and biodegradable sources like reductant and capping agents, have made a remarkable attraction toward nanotechnology. Piper betle (betel leaves) have been used in our Indian traditional medicine system for digestive and pancreatic lipase stimulant activities [8]. The leaves of Piper betle have been employed in traditional herbal remedies. Active phenolic compounds such as chavibetol, piperol, piperbetol, hydroxychavicol and eugenol are enriched in the betel leaves, among which eugenol is major phenolic possess remarkable chemotherapeutic and chemopreventive potential, and it is inexpensive and non-toxic [9-11].

Based on the preliminary study conducted in our laboratory, the method of synthesis of silver nanobioconjugates was optimized using the methanolic extracts of Piper betle leaves as well as their active phenolic ingredient eugenol (commercially available). The synthesized bioconjugates were also bioactive, as reflected by their antibacterial effect due to their nano size which was confirmed by the various characterization techniques [12]. Encouraged by these results. Therefore, the present study deals with the anticancer effect of silver nano-bio conjugates synthesis from Piper betle leaf extract and its active phenolic component, eugenol.

\section{MATERIALS AND METHODS}

\section{Synthesis of silver nano-bio conjugates}

Based upon the earlier research conducted in our laboratory, the method for nanobioconjugates synthesis was optimized and characterized, which confirmed that the sunlight exposure was rapid in synthesis [12]. The nanobioconjugates were synthesized by adding methanolic extract of Piper betle extract (PE) or diluted purified $100 \mu \mathrm{g}$ of eugenol (EU) to $1 \mathrm{mmol}$ silver nitrate (Sigma) solution in the ratio of 10:90. The mixture of extract or compound and silver nitrate solution was exposed to bright sunlight (12500-13500 lux) for $20 \mathrm{~min}$. After the exposure period, the mixture was centrifuged at $3500 \mathrm{~g}$ for $20 \mathrm{~min}$ and washed thrice with deionized water. The nanobioconjugates were dried and dissolved in the DMSO for the further study. 


\section{Culturing of KB cells}

The oral cancer cell line (KB) (Plate 1) were procured from National Center for Cell Sciences (NCCS), Pune, and used in this study. The cell lines were cultured and maintained in DMEM (Gibco) with 10\% FBS (PAA) and 1X penicillin-streptomycin (MP Biomedicals) as per standard procedures and maintained in a $\mathrm{CO} 2$ incubator (Innova, UK). The confluent grown cells were trypsinized using Trypsin-EDTA (PAA) and suspended in a fresh complete medium. The flasks were incubated in a CO2 incubator (Innova, UK) with 95\% humidity and 5\% CO2. For the experiments, the cells were counted using hemocytometer and 105 live cells/per milliliter were seeded for the further experiments.

\section{Culturing of buccal cells}

The protocol of collection and the use of non-cancerous cells from healthy human volunteers was scrutinized and approved by the Institutional Human Ethics Committee (AUW/IHEC-14-15/XPD-08).

The buccal cells (Plate 1) were collected from healthy human volunteers, who were not on any medication in the age group of 20 $30 \mathrm{y}$. The mouth was rinsed with $5 \mathrm{ml}$ of Listerine; then sterile soft wood scrapers were used to scrape the buccal cells from the buccal cavity. About $15 \mathrm{ml}$ of a sterile saline was used to rinse the mouth which was collected in a sterile beaker, the scraper was also washed with $10 \mathrm{ml}$ of sterile saline into the same sterile beaker. The cells were centrifuged at $300 \mathrm{~g}$ for $5 \mathrm{~min}$ and the pellet was resuspended in $1 \mathrm{ml}$ of sterile PBS. The suspended cells were treated with $1 \mathrm{X}$ penstrep (Penicillin-Streptomycin, from a 100X stock (MP Biomedicals, USA)), $12 \mu \mathrm{l} / \mathrm{ml}$ fluconazole (Cipla) and incubated for $30 \mathrm{~min}$ to remove any contamination. The cells were centrifuged at $300 \mathrm{~g}$ for 5 min and washed twice with sterile PBS. Then the buccal cells were resuspended in complete DMEM (supplemented with 2\% FBS, 1X Penstrep and $1.2 \mu \mathrm{g} / \mathrm{ml}$ fluconazole) in the cell culture flask. The cells were incubated in a $\mathrm{CO}_{2}$ chamber (Napco, UK) for $24 \mathrm{~h}$.

After $24 \mathrm{~h}$ of incubation, the buccal cells were transferred into a complete medium with 5\% FBS. Again, the buccal cells were incubated for another $24 \mathrm{~h}$ and the cells were collected by trypsinization, centrifuged as earlier and the cell count was determined using a hemocytometer. The live healthy cells $(105$ cells $/ \mathrm{ml})$ were seeded in a 6-well plate with complete medium and with nano bio conjugates synthesized from betel leaf extract, their respective pure compound, and their respective non-nano raw material. The exposure was done at $37^{\circ} \mathrm{C}$ for $24 \mathrm{~h}$. The cells were then harvested and centrifuged at 4000 rpm for 5 min, washed twice with sterile PBS and resuspended in PBS for the viability and staining analysis.

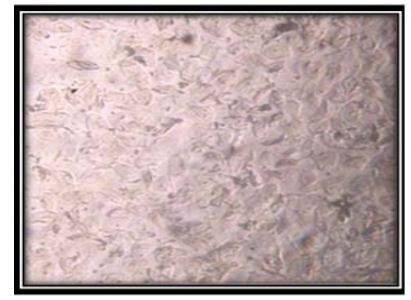

a) Human buccal cells

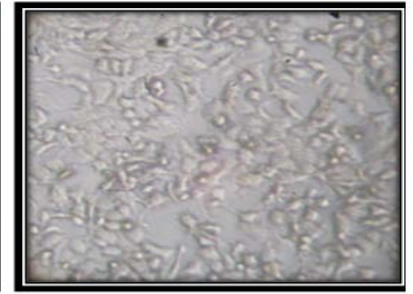

b) Human oral carcinoma (KB)
Plate 1

\section{Anticancer effect of nano bio conjugates}

The anticancer activity was analyzed by cell viability and staining techniques. The cell viability was determined by the MTT $[3(4,5-$ dimethly-thiazol-2-yl)-2,5-diphenyl tetrazolium bromide] reduction assay [13] and the apoptosis was evaluated by the $\mathrm{AO} / \mathrm{EtBr}$ staining method [14] using a fluorescent microscope (Nikon, Japan) using B2A filter at 40X magnification. Live and apoptotic cells were counted and discriminated to calculate the apoptotic ratio. Live cells appeared uniformly green. Apoptotic cells incorporate the ethidium bromide and show the chromatin condensation and nuclear fragmentation. The apoptotic ratio was calculated using the following formula.

$$
\text { Apoptotic ratio }=\frac{\text { Number of apoptotic cells }}{\text { Number of normal cells }}
$$

The assay and staining method were carried out in both the cancerous and non-cancerous cells. The following treatment groups were set up:

- Untreated (negative) control cells

- Cells treated with leaf extract/silver nanobioconjugates of $P$. betle

- Cells treated with eugenol/silver nanobioconjugates of eugenol

The parameters analyzed in this study were subjected to statistical analysis using SigmaStat (Version 3.1) statistical software. Statistical significance was determined by one-way ANOVA and the standard deviation value falls within \pm 1 to \pm 7 .

Cell cycle analysis was carried out by flow cytometry, to determine the phase of cell cycle arrest [15]. The cells were analyzed for the populations of sub- $\mathrm{G}_{0}, \mathrm{G}_{0} / \mathrm{G}_{1}, \mathrm{~S}$ and $\mathrm{G}_{2} / \mathrm{M}$ phases of the cell cycle by the software of flow cytometry (BD FACSVerse, USA).

\section{RESULTS}

The MTT assay was used to determine the influence of silver nanobioconjugates on the viability of oral cancer cells along with the non-transformed buccal cells. A dose and time dependent effect of silver nanobioconjugates synthesized from Piper betle leaf extract (PAgNP) and eugenol (EAgNP) was studied. A wide range of both silver nanobioconjugates $(2.5 \mu \mathrm{g}$ to $50 \mu \mathrm{g} / \mathrm{ml})$ and their extract alone. Based on the literature reports $50 \mu \mathrm{M} / \mathrm{ml}$ of the active component eugenol [16] was used in the study, at the exposure period of $24 \mathrm{~h}$. The Piper betle leaf extract, eugenol, and their nanobioconjugates showed a dose-dependent decrease in the viability of KB cells. The results showed that the viability was lower in the treatment of silver nanobioconjugates groups when compared with the extract and compound alone (fig. 1(i), 1(ii)). These observations show that the anticancer effect of both Piper betle leaf extract and its active phenolic component, eugenol, can be increased several folds by administering them as silver nanobioconjugates.

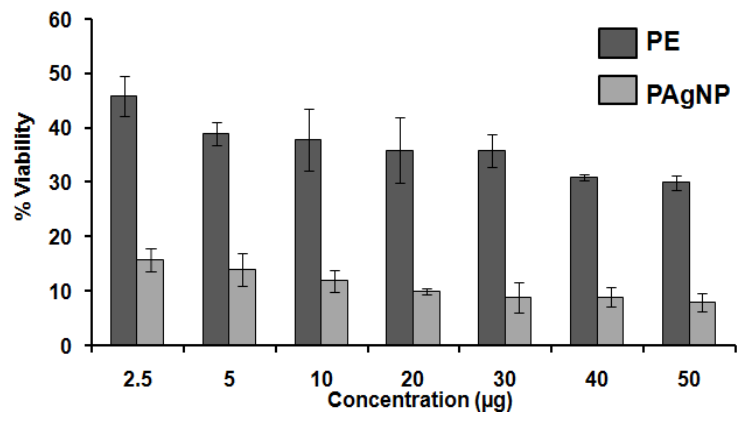

i) Silver nanobioconjugates from Piper betle leaf extract

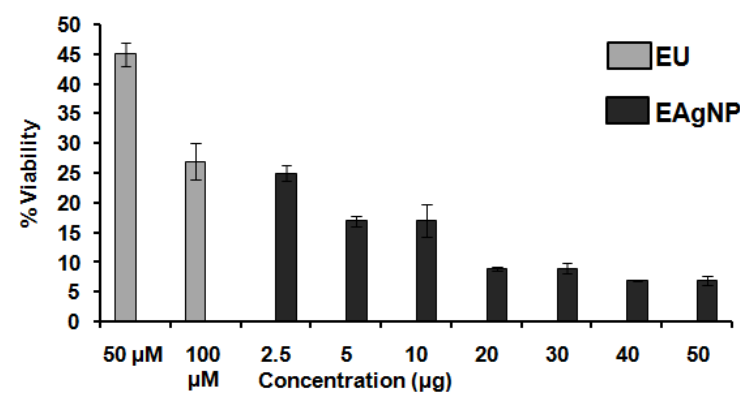

ii) Silver nanobioconjugates from eugenol

Fig. 1: Effect of silver nanobioconjugates synthesized from Piper betle leaves and their active component eugenol on the viability of $\mathrm{KB}$ cells ( $24 \mathrm{~h}$ treatment)

The bars are mean \pm Standard deviation of triplicates, (PE-Piper betle leaf extract, PAgNP-Silver nanobioconjugates from betle leaves, EUEugenol, EAgNP-Silver nanobioconjugates from eugenol)

The extent of cell death induced by the nanobioconjugates was very high at $24 \mathrm{~h}$ exposure period, therefore, the shorter exposure period 
of $16 \mathrm{~h}$ was studied. Similarly, as 24-h exposure results were obtained, KB cells showed high toxicity against all the dose levels (fig. 2). Again the silver nanobioconjugates with the dose range of $2.5 \mu \mathrm{g}$ and $5 \mu \mathrm{g} / \mathrm{ml}$ were tested for $12 \mathrm{~h}$ period. The results showed about $50 \%$ toxicity level, therefore, the $2.5 \mu \mathrm{g}$ concentration of silver nano bio conjugates was taken for the further study.
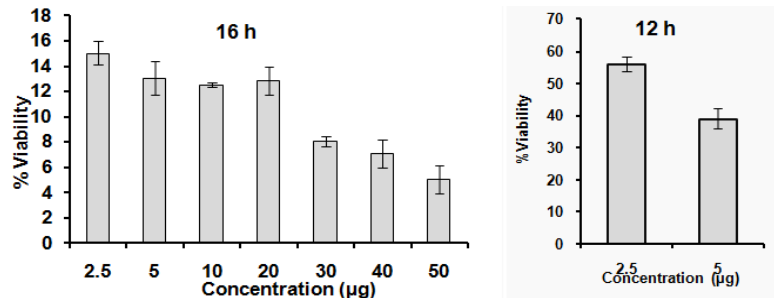

i) Silver nano bio conjugates from Piper betle leaf extract
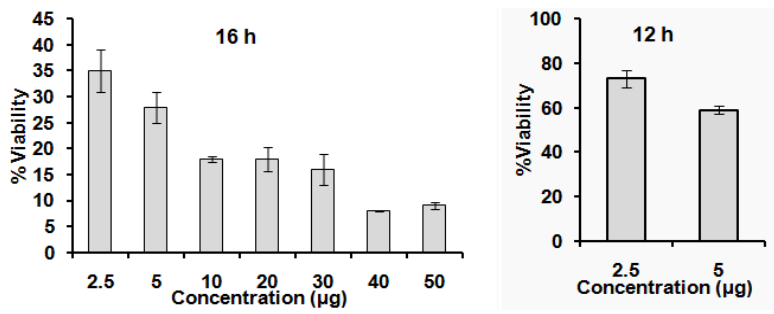

ii) Silver nano bio conjugates from eugenol

Fig. 2: Effect of silver nano bio conjugates synthesized from Piper betle leaves and their active component eugenol on the viability of KB cells (16 and $12 \mathrm{~h}$ treatment)

The values are mean \pm Standard deviation of triplicates
From the wide range of doses $2.5 \mu \mathrm{g}, 20 \mu \mathrm{g}$ and $50 \mu \mathrm{g} / \mathrm{ml}$ of silver nano bio conjugates synthesized from leaf extract and eugenol were selected for testing the cytotoxicity in the primary cultured buccal cells. The results (fig. 3(i), 3(ii)), revealed that both the nano bio conjugates did not affect the viability of the buccal cells at the various dose level tested, which confirmed the differential effect of Piper betle leaf extract and its phenolic component on cancerous and non-cancerous cells of the oral cavity.
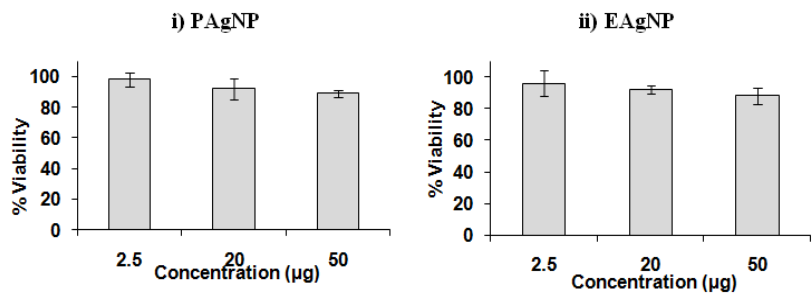

Fig. 3: Effect of silver nano bio conjugates on human buccal cells the values are mean \pm Standard deviation of triplicates

Following with the results of MTT assay, the type of cell death occurs in the cancer cells was studied by the AO/EtBr staining using a fluorescent microscope. From the microscopic study, it could be observed that the type of cell death observed was predominantly apoptosis. The number of apoptotic cells per 100 cells was counted in each treatment group, and the apoptotic index was calculated. From the results, it was observed that the leaf extract and its active component eugenol mediate the apoptosis process, whereas in the nanoform the apoptotic ratio was increased significantly (table 1 and Plate 2) The arrow marks in the plate 2 indicating the apoptotic cells.

Table 1: Effect of extract/compound/silver nanobioconjugates in KB cells and human buccal cells (AO/EtBr staining)

\begin{tabular}{llll}
\hline Treatment groups & \multicolumn{2}{l}{ Number of apoptotic cells/100 cells } & Human Buccal cells \\
\cline { 2 - 4 } & KB cells & Extract/Compound alone \\
\cline { 2 - 4 } & Extract/Compound alone & AgNP & $9 \pm 2$ \\
\hline Control & $7 \pm 2$ & $47 \pm 5$ a,b & $8 \pm 2$ \\
Piper betle & $34 \pm 5^{\mathrm{a}}$ & $55 \pm 2^{\mathrm{a}, \mathrm{b}, \mathrm{c}}$ & $11 \pm 1$ \\
Eugenol & $47 \pm 3^{\mathrm{a}, \mathrm{c}}$ & $11 \pm 2$ \\
\hline
\end{tabular}

The values are mean \pm Standard deviation of triplicates, aStatistically significant $(\mathrm{P}<0.05)$ compared to untreated control, bStatistically significant $(\mathrm{P}<0.05)$ compared to corresponding unconjugated extract/compound, 'Statistically significant $(\mathrm{P}<0.05)$ compared to the corresponding extract/compound/group

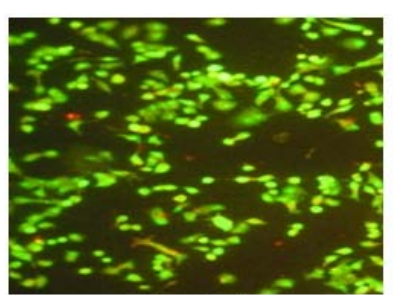

Control

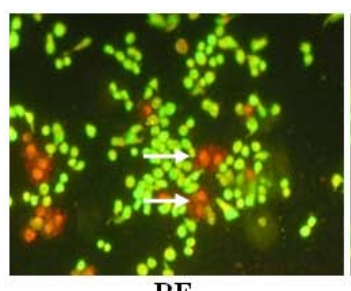

$\mathrm{PE}$

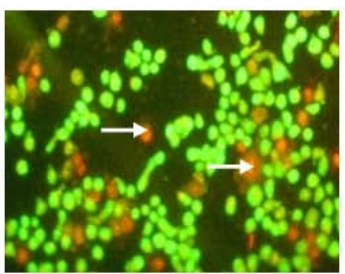

EU

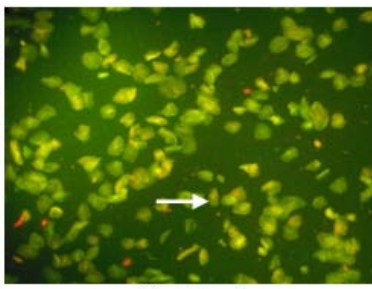

Control

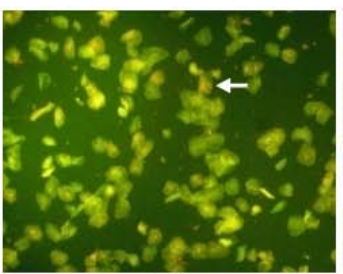

PE

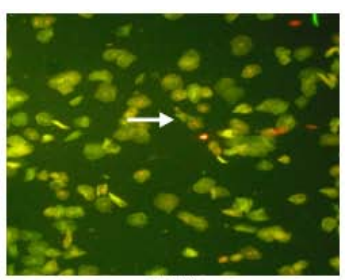

EU 


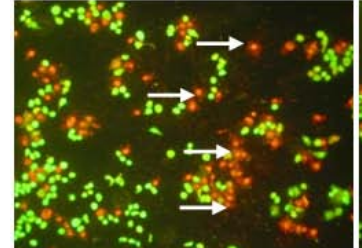

PAgNP

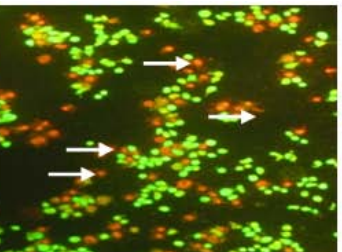

EAgNP

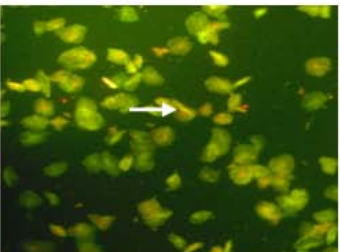

PAgNP

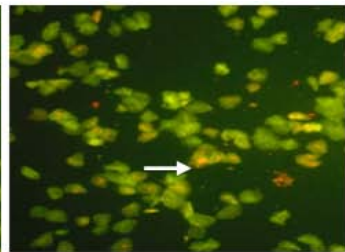

EAgNP

Plate 2: Effect of extract / Compound / silver nano bio conjugates on the KB cancer cells and non-cancerous buccal cells, PE - Piper betle leaf extract, EU - Eugenol, PAgNP - Silver nano bio conjugates from betel leaves, EAgNP - Silver nano bio conjugates from eugenol

The events of the cell cycle in the exposed cancer cells was analyzed by flow cytometry. The results showed that the nanobioconjugates exhibited the anticancer effect by shifting the cells into $\mathrm{S}$ phase, and G2/M phase compares with the non-conjugate betel extract and eugenol (fig. 4). The results obtained supported the earlier results obtained by MTT assay and staining technique, which proved that the effect of betel leaf extract and eugenol was more when they were administered as silver nano bio conjugates in the oral cancer cells.

\section{i) Scattergrams}

PE

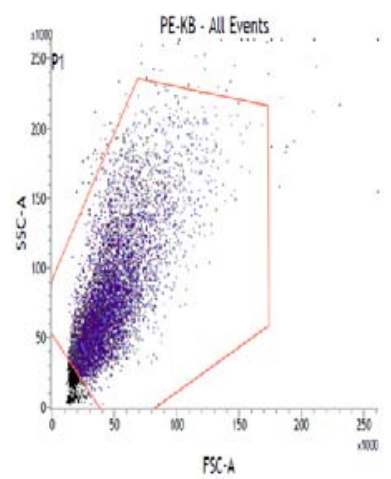

ii) Histograms

PE

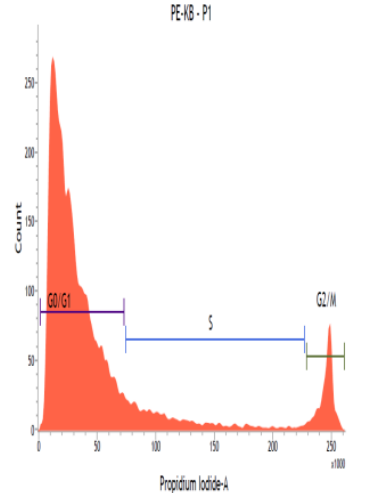

PAgNP

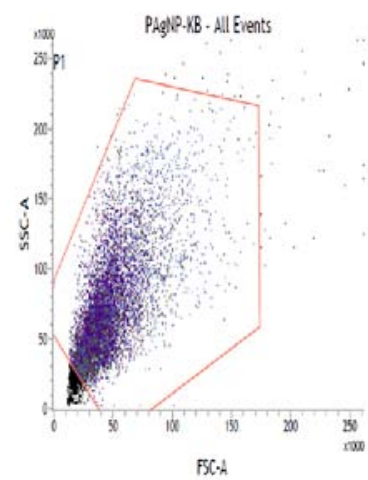

PAgNP
EU

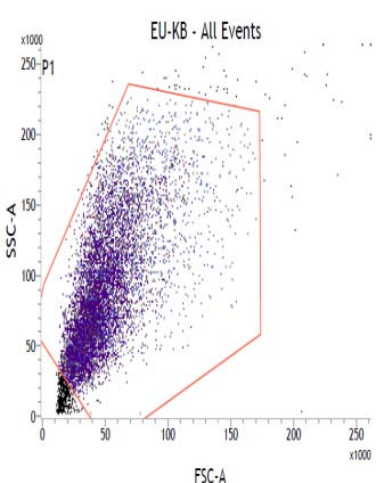

EU

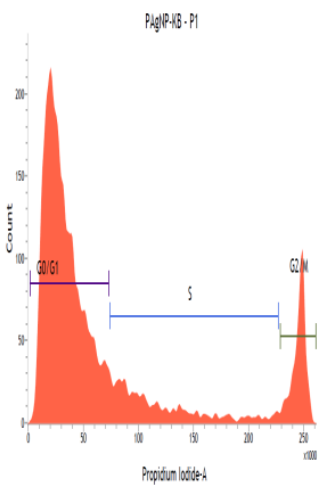

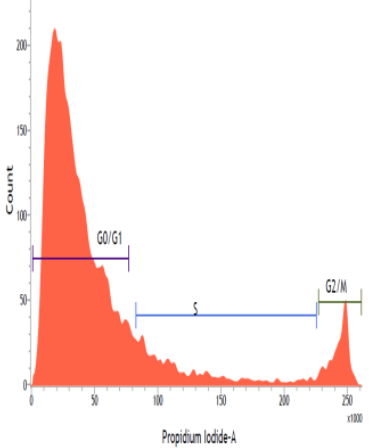

EAgNP

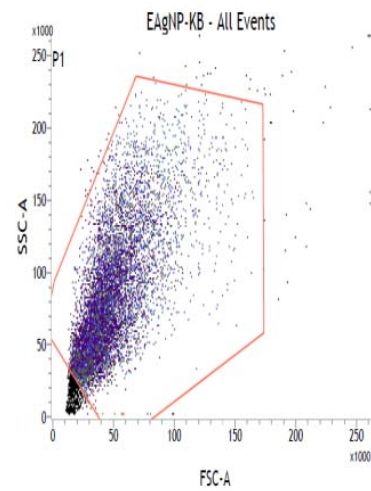

EAgNP

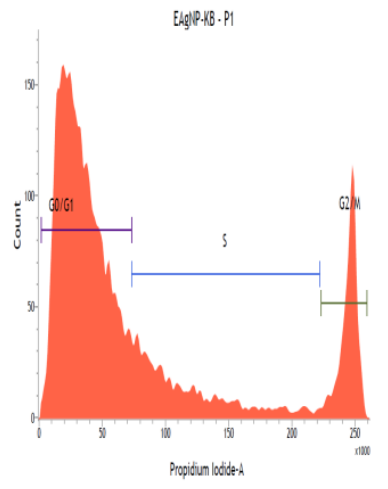

PE-Piper betle leaf extract, PAgNP-Silver nano bio conjugates from betle leaves, EU-Eugenol, EAgNP-Silver, nano bio conjugates from eugenol

Fig. 4: Effect of Piper betle leaf extract and its silver nano bio conjugates on cell cycle events in KB cells

\section{DISCUSSION}

The past ten years of research using metal nanoparticles such as silver, gold, copper, iron, titanium and ruthenium in preclinical research has shown promising anticancer properties [17]. Among the metal nanoparticles, silver and gold have been an attractive frontier of nanoparticle research because of their unique physicochemical properties in biomedical applications, such as bioimaging, biosensing, antimicrobial agents and cancer therapy [18].

Our results showed the strong anticancer activity of the silver nano bio conjugates synthesized. The extent of the anticancer effect was significantly more in the nano bio conjugates than their nonconjugated forms, proving that the anticancer activity of the test materials used can be enhanced markedly by preparing silver nano bio conjugates. The in vitro cytotoxicity assays have long been used for obtaining data on cell viability. Among these, MTT cell survival assay is used for analyzing and validating the cytotoxic potential of compounds [19]. Various reports on the anticancer activity of silver nanoparticles of plant-mediated extracts are available in the literature. The AgNPs synthesized from the ethanolic extract of rose petals showed a dosedependent decrease in the viability of human colon cancer HCT 15 cells [20]. Vasanth et al. [21] showed that the AgNPs of stem bark extract of Moringa oleifera possessed potent anticancer activity in human cervical carcinoma cells.

Followed by the cell viability assay, A0/EtBr staining was used to confirm the type of cell death caused by the silver nano bioconjugates, 
which was observed to be apoptosis in oral (KB). AO is a fluorescent dye that stains both dead and live cells, whereas EtBr stains only the dead cells, due to lost membrane integrity. Morphological changes have been reported in MCF-7 breast cancer cells treated with silver nanoparticles from Achillea biebersteinii using A0/EtBr staining [22]. Another study illustrated that nanosilver showed a stronger inhibitory effect on the liver cancer cells (HepG2) compared to the primary liver cells of mice, which was also observed using A0/EtBr staining [23]. In another study, silver nanoparticles of polyvinylpyrrolidone did not show any cytotoxicity in bone marrow cells, erythrocytes or human keratinocytes by AO/EtBr staining [24]. These reports lend further credibility to the results observed in the present study.

The silver nano bio conjugates showed a higher shift of cells from G0/G1 phase to the $\mathrm{S}$ phase and $\mathrm{G} 2 / \mathrm{M}$ phase compared to the extracts/compounds in KB cells. These results clearly showed the induction of apoptosis by the silver nano bio conjugates, which was higher than the respective non-conjugated forms. The arrest of cells in $\mathrm{G} 2 / \mathrm{M}$ phase has been recognized as representing a high level of cytotoxicity in several literature reports. The silver nanoparticles synthesized from ethanolic extracts of Phytolacca decandra, Gelsemium sempervirens, Hydrastis canadensis and Thuja occidentalis showed the highest peak in G2/M phase, which was suggested to indicate cytotoxic effect in human amelanotic melanoma (A375 cells) [25]. Similarly, the silver nanoparticles synthesized from mint, ginger, and coffee in HepG2 (hepatocellular liver carcinoma) and HeLa (human cervical cancer) caused cell cycle arrest in the G2/M phase [26]. Our results are in agreement with these reports. Thus, the silver nano bio conjugates synthesized from the plant source selected in this study exhibit stronger anticancer activity than the extracts and compound in their unconjugated form.

\section{CONCLUSION}

The findings of the present study, thus, validate and strengthen the method of synthesis of silver nano-bio conjugates from Piper betle leaves and their major polyphenol (eugenol) using a rapid, inexpensive and eco-friendly method. The anticancer properties of silver nano-bio conjugates were higher than their respective unconjugated forms, showing that the efficacy of their anticancer principles can be increased markedly by conjugating with silver to form nano bio conjugates.

\section{CONFLICTS OF INTERESTS}

Declared none

\section{REFERENCES}

1. Khan Z, Muller S, Ahmed S, Tonnies J, Nadir F, Samkange-Zeeb F. Quantitative review of oral cancer research output from Pakistan. Asian Pac J Cancer Prev 2015;6:4733-9.

2. Nair MK, Varghese C, Swaminathan R. Cancer: current scenario, intervention strategies, and projections, for 2015, NCMH Background Papers-Burden of Disease in India; 2015. p. 219-25.

3. Locatelli E, Naddaka M, Uboldi C, Loudos G, Fragogeorgi E, Molinari V, et al. Targeted delivery of silver nanoparticles and alisertib: In vitro and in vivo synergistic effect against glioblastoma. Nanomedicine 2014;9:839-49.

4. Kura AU, Fakuraz S, Hussein MZ, Arulselvan P. Nanotechnology in drug delivery: the need for more cell culture-based studies in screening. Chem Cent J 2014;8:46-52.

5. Panzarini E, Inguscio V, Tenuzzo BA, Carata E, Dini L. Nanomaterials and autophagy: new insights in cancer treatment. Cancers 2013;5:296-319.

6. Herrmann IK. How nanotechnology-enabled concepts could contribute to the prevention, diagnosis and therapy of bacterial infections. J Crit Care 2015;19:239-41.

7. Hemant K, Raizaday A, Sivadasu P, Uniyal S, Kumar SH. Cancer nanotechnology: nanoparticulate drug delivery for the treatment of cancer. Int J Pharm Pharm Sci 2015;7:40-6.

8. Pradhan D, Biswasroy P, Suri KA. Variation in the percentage content of hydroxychavicol in different extracts of Piper betle L. by altering the extraction parameters. Int J Pure Appl Sci Technol 2014;2:517-30.

9. Singh S, Saikia JP, Buragohain AK. A novel 'green' synthesize of colloidal silver nanoparticles (SNP) using Dillenia indica fruit extract. Colloids Surf B 2013;102:83-5.

10. Gundala SR, Aneja R. Piper betle leaf: a reservoir of potential xenohormetic nutraceuticals with cancer-fighting properties. Cancer Res 2014;7:477-86.

11. Cowing D, Powell A, Johnson M. Evaluation of different concentration doses of eugenol on the behavior of nephrops norvegicus. Aquaculture 2015;442:78-5.

12. Preethi P, Padma PR. Biocompatibility of biosynthesized silver nano bio conjugates derived from a methanolic extract of piper betle leaves. Indo Am J Pharm Res 2016;6:5661-70.

13. Igarashi $M$, Miyazawa $T$. The growth inhibiting effect of conjugated linoleic acid on a human hepatoma cell line Hep G2, is induced by a change in fatty acid metabolism but not the facilitation of lipid peroxidation in cells. Biochem Biophys Acta/Mol Cell Biol Lipids 2001;1530:162-71.

14. Parks DR, Bryan VM, Oi VT, Herzenberg LA. Antigen-specific identification and cloning of hybridomas with a fluorescenceactivated cell sorter. Proc Nat Acad Sci 1979;76:1962-6.

15. Krishan A. Rapid flow cytofluorometry analysis of mammalian cell cycle by propidium iodide staining. J Cell Biol 1975;66:188-93.

16. Jaganatha SK, Supriya to E. Antiproliferative and molecular mechanism of eugenol-induced apoptosis in cancer cells. Molecules 2012;17:6290-304.

17. Ceresa C, Bravin A, Cavaletti G, Pellei M, Santini C. The combined therapeutical effect of metal-based drugs and radiation therapy: the present status of research. Curr Med Chem 2014;21:2237-65.

18. Luo Z, Zheng K, Xie J. Engineering ultrasmall water-soluble gold and silver nanoclusters for biomedical applications. Chem Commun (Camb) 2014;50:5143-55.

19. Sumantran VN. Cellular chemosensitivity assays: an overview. Methods Mol Biol 2011;731:219-36.

20. Manikandan R, Manikandan B, Marimuthu PN, Raman T, Mahalingam A, Subramanian $\mathrm{P}$, et al. Synthesis of silver nanoparticles using Solanum trilobatum fruits extract and its antibacterial, cytotoxic activity against human breast cancer cell line MCF 7. Spectrochim Acta A Mol Biomol Spectrosc 2015;140:223-8.

21. Vasanth K, Ilango K, Mohankumar R, Agrawal A, Dubey GP. Anticancer activity of Moringa oleifera mediated silver nanoparticles on human cervical carcinoma cells by apoptosis induction. Colloids Surf B 2014;117:354-59.

22. Baharara J, Namvar F, Ramezani T, Mousavi M, Mohamad R. Silver nanoparticles biosynthesized using Achillea biebersteini flower extract: apoptosis induction in MCF-7 cells via caspase activation and regulation of Bax and Bcl-s gene expression. Molecules 2015;20:2693-706.

23. Faedmaleki F, Shirazi FH, Salarian A, Ashtiani HA, Rastegar H. Toxicity effect of silver nanoparticles on mice liver primary cel culture and HepG 2 cell line. Iran J Pharm Res 2014;13:235-42.

24. Huk A, Izak-Nau E, Reidy B, Boyles M, Duschl A, Lynch I, et al. Is the toxic potential of nanosilver dependent on its size? Part Fibre Toxicol 2014;11:65.

25. Das S, Das J, Samadder A, Bhattacharyya SS, Das D, Rahman A, et al. Biosynthesized silver nanoparticles by ethanolic extracts of Phytolacca decandra, Gelsemium sempervirens, Hydrastis canadensis and Thuja occidentalis induce differential cytotoxicity through $\mathrm{G}_{2} / \mathrm{M}$ arrest in A375 cells. Colloids Surf B 2013;101:325-36.

26. Chunyan W, Valiyaveettil S, Correlation of biocapping agents with cytotoxic effects of silver nanoparticles on human tumor cells. RSC Adv 2013;3:14329-38.

\section{How to cite this article}

- $\quad$ R Preethi, PR Padma. Anticancer activity of silver nanobioconjugates synthesized from piper betle leaves extract and its active compound eugenol. Int J Pharm Pharm Sci 2016;8(9):201-205. 